\section{Reviewing the revisions: what are the Australian Bureau of Statistics suicide figures really telling us?}

To THE EDITOR: For several years, the Australian Bureau of Statistics (ABS) has cautioned data users of likely underreporting of suicide statistics due to delays in coronial processes and (since 2006) exclusive reliance on the National Coronial Information System, which often contains incomplete information on cause of death. ${ }^{1}$ In 2009, the ABS introduced data revision processes that allowed additional information received to be added in two rounds of revisions at 12 and 24 months after the initial processing of coronercertified deaths. This assisted coders in assigning more specific causes of death, thereby replacing the previous default "accident" category for ambiguous cases.

These changes have increased reported suicide rates, predominantly due to parallel reductions in deaths assigned to "Other ill-defined and unspecified causes of mortality" (International Classification of Diseases, 10th revision [ICD-10] code R99), which have more than halved, and "Event of undetermined intent" (ICD-10 codes Y10-Y34, Y87.2), which have reduced by around twothirds. ${ }^{2,3}$ As these categories often represent "holding bays" for cases with insufficient information at initial processing, such decreases would be expected after the revisions. However, the figures remained inflated: in the 2006-2009 data (which have undergone two rounds of revision), ill defined causes of death remained more than double the levels recorded during the 1990s, and deaths of undetermined intent more than three times higher. ${ }^{3}$

Currently, the only reliable alternative source of suicide mortality data in Australia, albeit at the state level, is the Queensland Suicide Register (QSR). The differences between the two datasets have been

\begin{tabular}{|c|c|c|c|}
\hline \multicolumn{3}{|c|}{$\begin{array}{l}\text { Differences in Queensland suicide } \\
\text { QSR and the ABS, 2001-2009 } \\
\text { Rate per } 100000\end{array}$} & \multirow[b]{2}{*}{ Difference } \\
\hline Year & QSR & ABS & \\
\hline 2001 & 14.05 & 13.75 & $2.2 \%$ \\
\hline 2002 & 15.64 & 14.46 & $8.2 \%$ \\
\hline 2003 & 14.33 & 12.23 & $17.2 \%$ \\
\hline 2004 & 15.25 & 11.61 & $31.3 \%$ \\
\hline 2005 & 14.17 & 11.49 & $23.3 \%$ \\
\hline 2006 & 12.91 & $12.08(F)$ & $6.9 \%$ \\
\hline 2007 & 12.89 & $12.39(F)$ & $4.0 \%$ \\
\hline 2008 & 13.86 & $12.83(F)$ & $8.0 \%$ \\
\hline 2009 & 13.39 & $11.86(F)$ & $13.0 \%$ \\
\hline
\end{tabular}

3 Australian Bureau of Statistics. Causes of death, Australia, 2011. Canberra: ABS, 2013. (ABS Cat. No. 3303.0.)

4 De Leo D, Sveticic J. Suicide in Queensland, 2005-2007: mortality rates and related data. Brisbane: Australian Institute for Suicide Research and Prevention, 2012. detailed elsewhere. ${ }^{4}$ From 2003, the discrepancy between QSR data and ABS preliminary data on suicide grew exponentially, reaching $47.1 \%$ in 2007. ${ }^{4}$ Final revisions of ABS data from 2006 have reduced the gap to levels comparable to those seen during the 1990s and early 2000s (Box). However, the two datasets remain significantly different for 2003-2005, for which ABS data were not revised. It is reasonable to conclude that considerable numbers of suicides in these years remain misclassified.

Data users should be aware of these caveats when interpreting ABS statistics, particularly the recently announced $17 \%$ drop in suicide rate over the past decade. ${ }^{2}$ Continuous efforts to improve the reliability and validity of suicide data are of paramount importance for developing and evaluating suicide prevention programs.

Jerneja Sveticic Senior Research Assistant Samara McPhedran Senior Research Fellow Diego De Leo Director

Australian Institute for Suicide Research and Prevention, Griffith University, Brisbane, QLD.

j.sveticic@griffith.edu.au

Competing interests: No relevant disclosures. doi: 10.5694/mjal3.10203

1 Australian Bureau of Statistics. Causes of death, Australia, 2006. Canberra: ABS, 2008. (ABS Cat. No. 3303.0.)

2 Australian Bureau of Statistics. Suicides, Australia, 2010. Canberra: ABS, 2012. (ABS Cat. No. 3309.0.) considerable numbers of suicides in these years remain misclassified

Sveticic et al

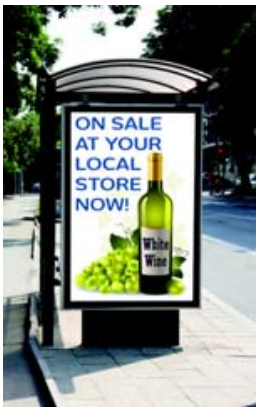

